\title{
Canonical Correlations between Body Postural Variables in the Sagittal Plane and Scoliotic Variables in School-Children
}

\author{
Jacek Wilczyński ${ }^{1}$, Katarzyna Bieniek ${ }^{2}$, Natalia Habik ${ }^{3}$, Sylwia Janecka ${ }^{3} \&$ Przemysław Karolak $^{3}$ \\ ${ }^{1}$ Department of Posturology, Hearing and Balance Rehabilitation, Faculty of Medicine and Health Sciences, Jan \\ Kochanowski University in Kielce, Poland \\ ${ }^{2}$ Faculty of Rehabilitation, University School of Physical Education in Krakow, Poland \\ ${ }^{3}$ Faculty of Medicine and Health Sciences, Jan Kochanowski University in Kielce, Poland \\ Correspondence: Jacek Wilczyński, Head of Posturology Department, Hearing and Balance Rehabilitation, \\ Faculty of Medicine and Healtha Sciences, Jan Kochanowski University, Kielce, Al. IX Wieków Kielc 19, \\ 25-317 Kielce, Poland. Tel: 48-603-703-926. E-mail: jwilczyński@onet.pl
}

Received: December 7, 2017

doi:10.5539/mas.v12n2p109
Accepted: December 18, 2017

Online Published: January 30, 2018

URL: https://doi.org/10.5539/mas.v12n2p109

\begin{abstract}
The aim of the study was analysis of the canonical correlations between body posture variables in the sagittal plane and scoliotic variables among school-children. The study included 28 girls aged 7-18. The Moiré photogrammetric method was used in the research. On the basis of the value of spine curvature angle, scoliotic posture: $1-9^{\circ}$; and scoliosis: $\geq 10^{\circ}$ were distinguished. There were $21(75 \%)$ with scoliotic posture and $7(25 \%)$ with scoliosis. In the canonical correlation regarding body posture variables in the sagittal plane, the largest shares concerned: trunk inclination angle (0.035), alpha angle (0.072), angle of chest kyphosis (0.383), length of lumbar lordosis-(-0.301), actual angle of lumbar lordosis/total spine length (-1.067). In the canonical correlation regarding scoliotic variables, the largest shares were related to: shoulder asymmetry - right higher $(-0.577)$, shoulder blade asymmetry - left higher (0.202), absolute pelvis tilt angle $(-0.811)$, coefficient of shoulder asymmetry relative to $\mathrm{C}_{7}(0.324)$, depth of primary curvature/total spine length $(0.420)$, primary curvature angle (0.032), length of secondary curvature/total spine length (-0.003). The high value of the canonical correlation coefficient despite lack of significance $(R=0.72963 ; p=0.40075)$ indicates the possibility of the occurrence of a strong correlation of both sets of variables that can be demonstrated with a larger sample size. In the selection of scoliosis treatment method, the size of the postural variables in the sagittal plane should be taken into account, and each patient's case should be individually considered.
\end{abstract}

Keywords: body postural variables in the sagittal plane, scoliotic posture, scoliosis, the Moiré photogrammetric method

\section{Introduction}

In the second half of the $20^{\text {th }}$ century, works on distal spine deformities in scoliosis patients appeared (Somerville, 1952). The physiological kyphosis of the chest in the course of idiopathic scoliosis has been described (Hefti, 2013). The term "rotational lordosis" has also been referred to as the pathological backbone 1.of the spine, which over time, changes into lateral distortion under the influence of vertebral rotation (Dubousset, 2011; Dubousset, 1994). In large scoliosis, the pathogenic significance of spinal anatomy increases (Dicson, 1999; Deacon \& Dicson, 1987). The column of the spine is called the inner hump (Deacon, Berkin \& Dickson, 1985; Cruickshank, 1989). From a functional point of view, it is more important than the external hump as it occupies the space required for internal organs (Tylman \& Fiałkowski, 1983; Janssen, de Wilde, Kouwenhoven \& Castelein, 2011).It increases with the progression of scoliosis and is responsible for distant chest complications (Negrini S, Negrini F, Fusco \& Zaina, 2011; Glowacki et al., 2013). At present, scoliosis is considered a multi-faceted distortion, in which, apart from deviation in the frontal plane, changes in the size of the curvatures in the sagittal plane as well the rotation and torsion of the vertebrae occur (Glowacki, Misterska, Adamczyk \& Latuszewska, 2013; Yaszay et al, 2017). Spinal curvature and its rotation are secondary and the reduction of thoracic kyphosis is primary, leading to progression of scoliosis (Iida et al, 2015; Corradin, Canavese, Dimeglio \& Dubousset, 2017). However, there are opinions about the size of lumbar lordosis. Some people think that it deepens in children with scoliosis (De Sèze \& Cugy, 2012; van Loon, 2008). Others claim the total opposite, i.e. 
that is becomes shallower (Illés et al., 2011; Joo, Rogers \& Donohoe, 2012). These are not purely theoretical considerations as the size and shape of these curvatures should be considered in the selection of treatment methods (Porte, Patte, Dupeyron \& Cottalorda, 2016). Based on the PNF (Proprioceptive Neuromuscular Facilitation) method used in scoliosis treatment, we use shoulder-blade movement patterns depending on the location and direction of the curvature, which causes the shoulder to be lowered or raised, and deepening or shallowing of chest kyphosis (Weiss, 2012). Properly chosen pelvic patterns result in lowering or raising the hips and deepening or shallowing lumbar lordosis (Park, 2017). The aim of the study was to analyze canonical correlations between postural variables in the sagittal plane and scoliotic variables in school-children.

\section{Method}

The study included 28 girls aged 7-18 with scoliotic posture or idiopathic scoliosis. The selection of test subjects was deliberate. Children attended therapy at the Intramural Centre for Corrective and Compensatory Gymnastics in Starachowice (Poland). The study was conducted in June 2011. All procedures performed in tests involving human participants were in accordance with the ethical standards of the institutional and/or national research committee and with the 1964 Helsinki declaration and its later amendments or comparable ethical standards. The guardians of the children were informed about the purpose of the study and expressed written consent for their children's participation in the study. The study was non-invasive and free of charge. The patients willingly participated in the study, and perceived it as a concern about their state of health. The photogrammetric Moiré method was used in postural tests. Spinous processes from C7 to S1 were marked on the back of tested subject using a marker, as well as the acromion, lower angles of the shoulder blades and the posterior superior iliac spine. The subject assumed a habitual position at the rear of the device at a distance of $3.2 \mathrm{~m}$. Stripes were projected onto the back, and the focusing of the lens allowed the Moire image to be obtained. The image of the spine was received by an optical system with a camera, then it was passed onto to the analogue monitor and finally, to the computer. In this way, a three-dimensional image of the back was formed. The following parameters of the posture in the sagittal plane were analysed: total spine length $(\mathrm{MM})$, trunk inclination angle $\left(^{\circ}\right)$, absolute trunk inclination angle $\left({ }^{\circ}\right)$, alpha angle $\left({ }^{\circ}\right)$, beta angle $\left({ }^{\circ}\right)$, gamma angle $\left({ }^{\circ}\right)$, length of chest kyphosis $(\mathrm{MM})$, length of chest kyphosis/total spine length (\%), angle of chest kyphosis $\left({ }^{\circ}\right)$, actual angle of chest kyphosis $\left({ }^{\circ}\right)$, actual angle of chest kyphosis/total spine length (\%), depth of chest kyphosis ( $\mathrm{mm})$, depth of chest kyphosis/total spine length (\%), absolute value of chest kyphosis depth/total spine length (\%), length of lumbar lordosis (mm), length of lumbar lordosis/total spine length (\%), lumbar lordosis angle $\left({ }^{\circ}\right)$, actual angle of lumbar lordosis $\left(^{\circ}\right)$, actual angle of lumbar lordosis/total spine length (\%), depth of lumbar lordosis (mm), depth of lumbar lordosis/total spine length (\%). Next, primary and secondary spinal curvature parameters were analysed: shoulder asymmetry - right higher $(\mathrm{mm})$, shoulder asymmetry - left higher $(\mathrm{mm})$, shoulder line angle $\left(^{\circ}\right)$, shoulder blade asymmetry - right higher $(\mathrm{mm})$, shoulder blade asymmetry - left higher $(\mathrm{mm})$, pelvis tilt angle $\left(^{\circ}\right)$, absolute value of pelvis tilt angle $\left({ }^{\circ}\right.$ ), pelvis rotation angle $\left({ }^{\circ}\right)$, pelvis rotation $\left(^{\circ}\right)$, shoulder/pelvis asymmetry coefficient $(\%)$, shoulder asymmetry coefficient - KK point $(\%)$, shoulder/ $\mathrm{C}_{7}$ asymmetry coefficient $(\%)$, length of curvature $(\mathrm{mm})$, length of curvature/total spine length (\%), depth of curvature ( $\mathrm{mm})$, depth of curvature/total spine length (\%), curvature angle $\left({ }^{\circ}\right)$, absolute value of curvature angle $\left({ }^{\circ}\right)$. Based on the size of the spinal curvature, the following were distinguished: scoliotic postures: $1-9^{\circ}$ and scoliosis: $\geq 10^{\circ}$.

The variables were verified for normality of distribution using the Shapiro-Wilk test. Factor analysis was used to determine the correlation between body posture variables in the sagittal plane and scoliotic variables as canonical correlations. Significant levels were assumed at $p<0.05$.

\section{Results and Discussion}

There were 21 children with scoliotic posture (75\%) and 7 with scoliosis 7 (25\%). Some of the body posture variables in the sagittal plane were strongly correlated with each other. Scoliotic variables also showed correlations between each other. On the other hand, canonical correlation analysis requires that each canonic variable (left and right sets) be independent an variable. Therefore, in order to identify variables that do not show dependence, factor analysis was used. As a result of exploratory factor analysis with Varimax rotation, among the 23 normalized variables characterizing the posture of the body in the sagittal plane, 5 orthogonal factors were identified. For individual factors, the highest absolute values of the factor load were for the following variables: Factor 1: angle of chest kyphosis ( $\mathrm{LC}=-0.882)$, Factor 2: trunk inclination angle ( $\mathrm{LC}=-0.944)$, Factor 3: alpha angle ( $\mathrm{LC}=0.919)$, Factor 4: length of lumbar lordosis $(\mathrm{LC}=0.960)$, Factor 5: actual angle of lumbar lordosis/total spine length ( $\mathrm{LC}=-0.847$ ). The share of these 5 factors in the total variance was significantly higher than the others. Selected orthogonal factors accounted for $89.3 \%$ of the total variance. 
Table 1. Factorial analysis of body posture in the sagittal plane variables (factorial loads $-L C$ )

\begin{tabular}{llllll}
\hline Body posture variables & Factor & Factor & Factor & Factor & Factor \\
& $\mathbf{1}$ & $\mathbf{2}$ & $\mathbf{3}$ & $\mathbf{4}$ & $\mathbf{5}$ \\
\hline Trunk inclination angle & -0.170 & $\mathbf{- 0 . 9 4 4}$ & 0.061 & -0.019 & 0.101 \\
Abs value of trunk inclination angle & -0.135 & -0.926 & 0.035 & 0.061 & 0.111 \\
\hline Alpha angle & -0.168 & -0.173 & $\mathbf{0 . 9 1 9}$ & 0.001 & -0.043 \\
Beta angle & 0.724 & 0.514 & 0.105 & -0.042 & 0.040 \\
\hline Gamma angle & 0.557 & -0.698 & 0.053 & 0.191 & 0.303 \\
Delta angle & 0.599 & -0.271 & 0.712 & -0.005 & 0.220 \\
\hline Compensation index & 0.526 & -0.393 & -0.604 & 0.154 & 0.261 \\
Absolute value of compensation index & -0.409 & 0.120 & 0.481 & -0.021 & -0.289 \\
\hline Length of chest kyphosis & 0.108 & -0.079 & -0.156 & 0.840 & 0.493 \\
Length of chest kyphosis / Total spine length & -0.046 & -0.002 & 0.053 & 0.049 & 0.809 \\
\hline Angle of chest kyphosis & $\mathbf{- 0 . 8 8 2}$ & 0.210 & -0.195 & -0.032 & -0.286 \\
Actual angle of chest kyphosis & 0.384 & -0.159 & -0.125 & 0.458 & 0.730 \\
\hline Actual angle of chest kyphosis / Total spine length & 0.445 & -0.167 & -0.027 & -0.088 & 0.838 \\
Depth of chest kyphosis & 0.874 & 0.296 & -0.086 & 0.036 & 0.270 \\
\hline Depth of chest kyphosis / Total spine length & 0.866 & 0.322 & -0.066 & -0.154 & 0.254 \\
Absolute depth of chest kyphosis / Total spine length & 0.846 & 0.365 & 0.019 & -0.129 & 0.197 \\
\hline Length of lumbar lordosis & -0.075 & 0.005 & 0.045 & $\mathbf{0 . 9 6 0}$ & -0.144 \\
Length of lumbar lordosis / Total spine length & -0.348 & 0.185 & 0.432 & 0.252 & -0.681 \\
\hline Angle of lumbar lordosis & -0.318 & -0.240 & -0.886 & 0.150 & -0.027 \\
Actual angle of lumbar lordosis & -0.300 & 0.055 & -0.092 & 0.734 & -0.577 \\
\hline Actual angle of lumbar lordosis / Total spine length & -0.434 & 0.141 & 0.059 & 0.128 & $\mathbf{- 0 . 8 4 7}$ \\
Depth of lumbar lordosis & 0.324 & 0.675 & 0.504 & 0.229 & -0.043 \\
\hline Depth of lumbar lordosis / Total spine length & 0.263 & 0.696 & 0.562 & 0.013 & -0.133 \\
Baseline value & 5.760 & 4.256 & 3.615 & 2.650 & 4.261 \\
\hline Share & 0.250 & 0.185 & 0.157 & 0.115 & 0.185 \\
Total share of values & 0.250 & 0.435 & 0.593 & 0.708 & $\mathbf{0 . 8 9 3}$ \\
\hline
\end{tabular}

Then, from among the normalized scoliotic variables, the following 7 factors were identified: Factor 1: length of secondary curvature /total spine length $(\mathrm{LC}=0.973)$, Factor 2: primary curvature angle ( $\mathrm{LC}==-0.933)$, Factor 3 : depth of primary curvature/total spine length $(\mathrm{LC}=0.967)$, Factor 4 : coefficient of shoulder asymmetry relative to $\mathrm{C}_{7}(\mathrm{LC}=0.867)$, Factor 5: absolute value of pelvis tilt angle $\left({ }^{\circ}\right)(\mathrm{LC}=0.797)$, Factor 6: shoulder blade asymmetry - left higher $(\mathrm{mm})(\mathrm{LC}=0.786)$, Factor 7: shoulder asymmetry - right higher $(\mathrm{LC}=0.834)$. The emerged orthogonal factors accounted for $86.3 \%$ of the total variance. In the canonical correlation regarding variables of body posture in the sagittal plane, the largest shares were related to: trunk inclination angle (0.035), alpha angle, (0.072), angle of chest kyphosis (0.383), length of lumbar lordosis (-0.301), actual angle of lumbar lordosis/total spine length (-1.067).

Table 2. Factorial analysis of scoliotic variables (factorial loads $-L C$ )

\begin{tabular}{|c|c|c|c|c|c|c|c|}
\hline Scoliotic variables with open eyes & $\begin{array}{l}\text { Facto } \\
\mathbf{r} \\
1\end{array}$ & $\begin{array}{l}\text { Facto } \\
\text { r } \\
2\end{array}$ & $\begin{array}{l}\text { Facto } \\
\mathbf{r} \\
\mathbf{3}\end{array}$ & $\begin{array}{l}\text { Facto } \\
\text { r } \\
4\end{array}$ & $\begin{array}{l}\text { Facto } \\
\text { r } \\
5\end{array}$ & $\begin{array}{l}\text { Facto } \\
\text { r } \\
6\end{array}$ & $\begin{array}{l}\text { Facto } \\
\mathbf{r} \\
7 \\
\end{array}$ \\
\hline Shoulder asymmetry - right higher & 0.225 & 0.286 & 0.169 & 0.025 & -0.035 & -0.106 & 0.834 \\
\hline Shoulder asymmetry- left higher & 0.071 & -0.305 & 0.096 & -0.064 & 0.456 & 0.618 & -0.429 \\
\hline Shoulder line angle & 0.075 & -0.406 & 0.002 & 0.062 & 0.164 & 0.327 & -0.733 \\
\hline Absolute shoulder line angle & 0.335 & -0.211 & 0.263 & 0.098 & 0.661 & 0.428 & 0.119 \\
\hline Shoulder blade asymmetry - right higher & 0.096 & 0.034 & 0.206 & 0.072 & 0.020 & -0.778 & -0.053 \\
\hline Shoulder blade asymmetry - left higher & 0.196 & 0.139 & 0.058 & 0.257 & 0.015 & 0.786 & -0.061 \\
\hline Pelvis tilt angle & 0.026 & 0.110 & -0.080 & -0.265 & 0.785 & 0.008 & -0.169 \\
\hline Absolute pelvis tilt angle & -0.266 & -0.149 & 0.076 & 0.110 & 0.797 & -0.060 & -0.108 \\
\hline Pelvis rotation angle & 0.015 & -0.299 & 0.291 & -0.726 & -0.111 & -0.266 & -0.177 \\
\hline Absolute pelvis rotation angle & 0.061 & -0.171 & 0.267 & -0.010 & -0.148 & 0.389 & 0.682 \\
\hline Coefficient of shoulder asymmetry $-\mathrm{KK}$ & -0.092 & -0.164 & -0.083 & 0.634 & 0.110 & 0.493 & -0.382 \\
\hline $\begin{array}{l}\text { Coefficient of shoulder asymmetry relative to } \\
\mathrm{C}_{7}\end{array}$ & 0.091 & -0.197 & -0.042 & 0.867 & -0.234 & -0.134 & -0.022 \\
\hline Length of primary curvature & -0.882 & 0.012 & 0.133 & -0.092 & 0.038 & -0.034 & 0.041 \\
\hline Length of primary curvature / Total spine length & -0.971 & -0.060 & 0.113 & 0.035 & -0.044 & 0.016 & 0.033 \\
\hline Depth of primary curvature & -0.119 & 0.086 & 0.960 & -0.100 & 0.040 & -0.064 & 0.085 \\
\hline
\end{tabular}




\begin{tabular}{|c|c|c|c|c|c|c|c|}
\hline Depth of primary curvature / Total spine length & -0.106 & 0.065 & 0.967 & -0.072 & 0.034 & -0.074 & 0.071 \\
\hline Primary curvature angle & -0.036 & -0.933 & -0.093 & 0.029 & 0.032 & 0.064 & -0.136 \\
\hline Absolute secondary curvature angle & 0.167 & -0.007 & 0.960 & -0.077 & 0.059 & 0.006 & 0.126 \\
\hline Length of primary curvature & 0.933 & 0.068 & -0.115 & -0.088 & 0.040 & -0.032 & -0.003 \\
\hline $\begin{array}{l}\text { Length of secondary curvature / Total spine } \\
\text { length }\end{array}$ & 0.973 & 0.046 & 0.124 & -0.034 & 0.034 & -0.002 & -0.035 \\
\hline Depth of secondary curvature & 0.802 & 0.079 & & .109 & -0.124 & 0.106 & 0.275 \\
\hline $\begin{array}{l}\text { Depth of secondary curvature / Total spine } \\
\text { length }\end{array}$ & 0.812 & 0.065 & 0.328 & 0.125 & -0.129 & 0.112 & 0.240 \\
\hline Secondary curvature angle & & & & & -0.096 & 0.044 & 0.173 \\
\hline Absolute secondary curvature angle & 0.725 & 0.239 & 0.539 & -0.062 & -0.046 & 0.064 & 0.137 \\
\hline Baseline value & & 2.396 & & & 2.083 & 2.439 & 2.352 \\
\hline Share & 0.242 & 0.100 & 0.154 & 0.080 & 0.087 & 0.102 & 0.098 \\
\hline Total share value & 0.242 & 0.342 & 0.496 & 0.576 & 0.663 & 0.765 & 0.863 \\
\hline
\end{tabular}

In the canonical relation regarding scoliotic variables, the largest shares regarded: shoulder asymmetry - right higher (-0.577), shoulder blade asymmetry - left higher (0.202), absolute pelvis tilt angle (-0.811), coefficient of shoulder asymmetry relative to $\mathrm{C}_{7}-(0.324)$, depth of primary curvature/total spine length $(0.420)$, primary curvature angle (0.032), length of secondary curvature/total spine length $(-0.003)$. The high value of the canonical correlational coefficient despite lack of significance $\left(\mathrm{R}=0.72963 ; \chi^{2}(35)=36.460 ; p=0.40075\right)$ indicates a strong possible correlation of both sets of variables able to be demonstrated with a larger sample size.

Table 3. Canonical weights and summary of canonical analysis

\begin{tabular}{|c|c|c|c|c|c|c|c|}
\hline \multicolumn{4}{|c|}{ Variables of body posture in the sagittal plane } & \multicolumn{4}{|c|}{ Scoliotic variables } \\
\hline \multicolumn{4}{|c|}{ Left set (5) } & \multirow{2}{*}{\multicolumn{4}{|c|}{$\begin{array}{c}\text { Right set (7) } \\
76.81 \%\end{array}$}} \\
\hline Isolated variation & & $100.00 \%$ & & & & & \\
\hline Total redundancy & & $29.70 \%$ & & & $18.31 \%$ & & \\
\hline $\begin{array}{l}\text { Variables of body posture } \\
\text { in the sagittal plane }\end{array}$ & $\begin{array}{c}\text { Elem } \\
1\end{array}$ & $\begin{array}{l}\text { Elem } \\
2\end{array}$ & $\begin{array}{c}\text { Elem } \\
3\end{array}$ & Variables & $\begin{array}{c}\text { Elem } \\
1\end{array}$ & $\begin{array}{l}\text { Elem } \\
2\end{array}$ & $\begin{array}{c}\text { Elem } \\
3\end{array}$ \\
\hline Trunk inclination angle & 0.035 & -0.853 & 0.278 & $\begin{array}{l}\text { Shoulder } \\
\text { asymmetry - } \\
\text { right higher }\end{array}$ & -0.577 & 0.023 & 0.088 \\
\hline Alpha angle & 0.072 & -0.364 & -0.285 & $\begin{array}{c}\text { Shoulder blade } \\
\text { asymmetry - left } \\
\text { higher }\end{array}$ & 0.202 & -0.218 & -0.402 \\
\hline Angle of chest kyphosis & 0.383 & -0.098 & -0.832 & $\begin{array}{l}\text { Absolute pelvis } \\
\text { tilt angle }\end{array}$ & -0.811 & -0.216 & -0.513 \\
\hline Length of lumbar lordosis & -0.301 & -0.095 & -0.713 & $\begin{array}{l}\text { Coefficient of } \\
\text { shoulder } \\
\text { asymmetry } \\
\text { relative to } \mathrm{C}_{7}\end{array}$ & -0.324 & 0.574 & 0.430 \\
\hline \multirow[t]{3}{*}{$\begin{array}{l}\text { Actual angle of lumbar } \\
\text { lordosis / Total spine } \\
\text { length }\end{array}$} & -1.067 & -0.044 & 0.748 & $\begin{array}{l}\text { Depth of } \\
\text { primary } \\
\text { curvature /Total } \\
\text { spine length }\end{array}$ & 0.420 & 0.456 & -0.390 \\
\hline & & & & $\begin{array}{l}\text { Primary } \\
\text { curvature angle }\end{array}$ & 0.032 & -0.167 & 0.366 \\
\hline & & $2963 ;$ & & $\begin{array}{c}\text { Length of } \\
\text { secondary } \\
\text { curvature /Total } \\
\text { spine length } \\
460 ; \boldsymbol{p}=0.40075\end{array}$ & -0.003 & -0.642 & 0.112 \\
\hline
\end{tabular}

Physiological chest kyphosis is a natural spinal flexure, intertwined between cervical and lumbar lordosis, thereby affecting the size of these two curves. Correct chest kyphosis guarantees proper statics of the spine and the entire trunk, including the body's centre of gravity. It rotationally stabilizes the spine (Skalli et al, 2017), provides cushioning and allows the physiological movement of the spine. Correctly developed thoracic kyphosis affects respiratory function. This is possible by providing the right anterior-posterior thoracic dimension and lung capacity. In addition, chest kyphosis allows the proper movement of the chest, depending on the correct axis of rotation of the ribs and vertebrae and the amplitude of the rib movement. The major morphological defect in 
idiopathic scoliosis is the excessive length of the frontal spinal column relative to the length of the posterior ones. Within the area of the primary curvature of chest scoliosis, each vertebra is in a lordotic position with respect to the vertebra above and below. This results in the reduction of kyphosis or even its lordosization (Kotwicki et al, 2013). Turning the spine around the long axis causes pathological frontal tilt leading to lateral curvature. Since idiopathic trunk scolioses are lordo-scolioses, it is necessary to explain the observation that many patients are diagnosed with gyperhyphosis (Dubousset, 1994). Actual kyphosis occurs on the combination of two structural bends. Within each of them, the axial rotation of the vertebrae is directed in opposite directions. On the combination of the two bends, the rotation of the stems causes the continuity of the frontal column of the spine, which leads to the kyphotic bend of both lobotically stiffened areas relative to each other (Deacon \& Dicson, 1987). The progression of thoracic scoliosis can occur to such large values of the axial rotation angle that lateral flexion is revealed in the sagittal plane as kyphosis. Despite the superficial image of kyphoscoliosis, the vertebrae remain in a lordotic position with respect to each other (Deacon, Berkin \& Dickson, 1985). Kyphosis is a natural component of the spine torsion process in lumbar and chest-lumbar scoliosis. Kyphosis may occur in the proximal thoracic spine as postural compensation of the lower lordotic part. In ways different from thoracic scoliosis, lumbar-chest and lumbar scoliosis develop. Initially, the lateral movement of the spine (lateral flexion of the spine in the shape of an arch) is greatest. Then, the rotation of the vertebrae around the long axis of the spine enlarges the curvature in the frontal plane, causing the lumbar muscle or thoracic lobe to be prominent, which is accompanied by a decrease in lumbar lordosis (Somoskeöy, Tunyogi-Csapó, Bogyó \& Illés, 2012). Curvature of chest kyphosis (flat back), scoliosis with reduced lateral mobility, scoliosis with short arch curvature, high rotation and structural changes in vertebral bodies cannot be attributed a positive outcome. The formation of chest scoliosis involves the displacement of 4-6 thoracic vertebrae initially in the sagittal plane (front tilt of thoracic spine) (Glowacki, Misterska, Adamczyk, \& Latuszewska, 2013). In this way, physiological kyphosis of the chest is reduced, the back becomes clinically flat. It should be noted that a flat back may occur as a so-called single-plane postural defect, not heading in the direction of scoliosis. Scoliosis is also accompanied by rotational and lateral displacement (Glowacki, Misterska, Adamczyk, \& Latuszewska, 2013). At this stage, there is no change in the shape of the vertebrae (vertebrae torsion), but only a three-plane change in their spatial orientation (spinal torsion). The frontal, core-disc column of the spine becomes relatively too long in relation to the two rear columns. One-plane (frontal) flexion of the spine may occur. This is qualified as scoliotic posture that does not develop into scoliosis. Occasionally, segmental rotation of the vertebrae without lateral curvature (single-plane defect in the transverse plane) is also encountered. A rib-bone hump occurs during bending but the radiograph does not show any curvature (Tikoo, Kothari, Shah \& Nene, 2017). The main goal of a another study was to determine the types of body posture of boys, 10 to 13 years of age, by means of the body posture assessment method based on Posture Image Analyzer software. The results should enable better understanding of postural issues, as well as timely and more precise selection of kinesiotherapeutic procedures. Values of 5 front view and 4 sagittal view indicators of standing body posture were measured by means of subjects' photographs and Image Posture Analyzer Cluster analysis software (K-means method) revealed three types of body posture in both the anterior and sagittal plane. Their characteristics were determined with discriminant analysis. In sagittal indicators, three posture types are recognizable: (a) correct sagittal body posture (29.3\%), (b) mild impaired sagittal body posture $(41.8 \%)$, (c) marked impaired sagittal body posture $(28.9 \%)$. In anterior indicators, there are also three posture types recognizable: (a) correct anterior body posture $(19.4 \%)$, (b) mild scoliotic body posture in the lumbar region (47.6\%), (c) mild scoliotic body posture with double curvature (33\%) (Jada et al, 2017). However, in another similar work, it was shown that for a normal spine, vector projections in the transverse plane are aligned with the posterior-anterior anatomical axis. For a scoliotic spine, vector projections in the horizontal plane provide information on the lateral decompensation of the spine and the lateral displacement of vertebrae. In the horizontal plane view, vertebral rotation and projections of the sagittal curvatures can also be analyzed simultaneously. The use of the posterior-anterior vertebral vector facilitates the understanding of the 3D nature of scoliosis (Pausić \& Dizdar, 2011). The used approach is simple. These results are sufficient for the first visual analysis supplying significant clinical information in all three anatomical planes. This visualization represents a reasonable compromise between mathematical purity and practical use (Illés, Tunyogi-Csapó \& Somoskeöy, 2017). In a different study, it was also shown that the angle size of the chest kyphosis and lumbar lordosis in girls with scoliosis and scoliotic posture were within normal limits. Forward trunk inclination was noticed. No significant difference in spinal curvature was found between age groups (Wilczyński, 2012).

\section{Conclusion}

In the case of body postural variables in the sagittal plane, the largest shares concerned: trunk inclination angle, alpha angle, angle of chest kyphosis, length of lumbar lordosis, actual angle of lumbar lordosis/total spine length. 
On the side of scoliotic variables, the largest shares were related to: shoulder asymmetry - right higher, shoulder blade asymmetry - left higher, absolute pelvis tilt angle, coefficient of shoulder asymmetry relative to $\mathrm{C}_{7}$, depth of primary curvature/total spine length, primary curvature angle, length of secondary curvature/total spine length. High values of canonical correlations despite lack of significance indicate the possibility that a strong correlation will occur between body posture variables and those of postural stability that can be distinguished with a larger sample size. In the selection of scoliosis treatment method, the size of postural variables in the sagittal plane should be taken into account and each patient's case should be individually considered.

\section{References}

Corradin, M., Canavese, F., Dimeglio, A., \& Dubousset, J. (2017). Cervical sagittal alignment variations in adolescent idiopathic scoliosis patients treated with thoraco-lumbo-sacral orthosis. Eur Spine J., 26(4),1217-1224. https://doi.org/10.1007/s00586-016-4884-7

Cruickshank, J. L., Koike, M., \& Dickson, R. A. (1989). Curve patterns in idiopathic scoliosis. A clinical and radiographic study. J Bone Joint Surg Br, 71(2), 259-63.

De Sèze, M., \& Cugy, E. (2012). Pathogenesis of idiopathic scoliosis: A review. Ann Phys Rehabil Med, 55(2), 128-138.

Deacon, P., \& Dickson, R. A. (1987). Vertebral shape in the median sagittal plane in idiopathic thoracic scoliosis. A study of true lateral radiographs in 150 patients. Orthopedics, 10(6), 893-5.

Deacon, P., Berkin, C. R., \& Dickson, R. A. (1985). Combined idiopathic kyphosis and scoliosis. An analysis of the lateral spinal curvatures associated with Scheuermann's disease, J Bone Joint Surg Br, 67(2), 189-92.

Dickson, R. A. (1999). Spinal deformity--adolescent idiopathic scoliosis. Nonoperative Treatment, Spine, 15, 24(24), 2601-6.

Dubousset, J. (1994). Three-dimensional analysis of the scoliotic deformity. In SL Weinstein (Ed.), The pediatric spine: principles and practice (pp.479-496). New York: Raven Press.

Dubousset, J. (2011). Reflections of an orthopaedic surgeon on patient care and research into the condition of scoliosis. J Pediatr Orthop, 31(1), S1-8. https://doi.org/10.1097/BPO. 0b013e3181f73beb

Glowacki, M., Misterska, E., Adamczyk, K., \& Latuszewska, J. (2013). Changes in Scoliosis Patient and Parental Assessment of Mental Health in the Course of Cheneau Brace Treatment Based on the Strengths and Difficulties Questionnaire. J Dev Phys Disabil, 25(3), 325-342.

Glowacki, M., Misterska, E., Adamczyk, K., \& Latuszewska, J. (2013). Prospective Assessment of Scoliosis-Related Anxiety and Impression of Trunk Deformity in Female Adolescents Under Brace Treatment. J. Dev Phys Disabil, 25(2), 203-220.

Hefti, F. (2013). Pathogenesis and biomechanics of adolescent idiopathic scoliosis (AIS). J. Child Orthop, 7(1), 17-24. https://doi.org/10.1007/s11832-012-0460-9

Iida, T., Ohyama, Y., Katayanagi, J., Ato, A., \& Mine, K., et al. (2015). Differences between pre-existing type and de novo type left convex thoracolumbar/lumbar scoliosis. Scoliosis. https://doi.org/10.1186/1748-7161-10-S2-S6

Illés, T., Tunyogi-Csapó, M., \& Somoskeöy, S. (2011). Breakthrough in three-dimensional scoliosis diagnosissignificance of horizontal plane view and vertebra vectors. Eur Spine J., 20, 135-143.

Illés, T.S., Burkus, M., Somoskeőy, S., \& Lauer, F., et al. (2017). The horizontal plane appearances of scoliosis: what information can be obtained from top-view images? Int Orthop, 11. https://doi.org/10.1007/s00264-017-3548-5.

Jada, A., Mackel, C. E., Hwang, S. W., \& Samdani, A. F., et al. (2017). Evaluation and management of adolescent idiopathic scoliosis: A review. Neurosurg Focus, 43(4), E2. https://doi.org/10.3171/2017.7.FOCUS17297

Janssen, M. M., de Wilde, R. F., Kouwenhoven, J. W., \& Castelein, R. M. (2011). Experimental animal models in scoliosis research: a review of the literature. Spine J., 11(4), $347-58$. https://doi.org/10.1016/j.spinee.2011.03.010

Joo, S., Rogers, K. J., \& Donohoe, M. (2012). Prevalence and patterns of scoliosis in children with multiple pterygium syndrome. J Pediatr Orthop, 2, 190-195.

Kotwicki, T., Chowanska, J., Kinel, E., \& Czaprowski, D., et al. (2013). Optimal management of idiopathic 
scoliosis in adolescence, Adolesc Health Med Ther, 4, 59-73.

Negrini, S., Negrini, F., Fusco, C., \& Zaina, F. (2011). Idiopathic scoliosis patients with curves more than 45 Cobb degrees refusing surgery can be effectively treated through bracing with curve improvements. Spine J., 11(5), 369-80. https://doi.org/10.1016/j.spinee.2010.12.001

Park, J. H., Jeon, H. S., \& Park, H. W. (2017). Effects of the Schroth exercise on idiopathic scoliosis: A meta-analysis. Eur J Phys Rehabil Med, 2. https://doi.org/10.23736/S1973-9087.17.04461-6

Pausić, J., \& Dizdar, D. (2011). Types of body posture and their characteristics in boys 10 to 13 years of age. Coll Antropol, 35(3), 747-54.

Porte, M., Patte, K., Dupeyron, A., \& Cottalorda, J. (2016). Exercise therapy in the treatment of idiopathic adolescent scoliosis: Is it useful? Arch Pediatr, 23(6), 624-8. https://doi.org/10.1016/j.arcped.2016.03.004

Skalli, W., Vergari, C., Ebermeyer, E., \& Courtois, I., et al. (2017). Early Detection of Progressive Adolescent Idiopathic Scoliosis: A Severity Index. Spine, 1, 42(11), 823-830. https://doi.org/10.1097/BRS.0000000000001961.

Somerville, E. W. (1952). Rotational lordosis; the development of single curve. J Bone Joint Surg Br, 34-B(3), 421-7.

Somoskeöy, S., Tunyogi-Csapó, M., Bogyó, C., \& Illés, T. (2012). Clinical validation of coronal and sagittal spinal curve measurements based on three-dimensional vertebra vector parameters. Spine J., 12, 960-968.

Tikoo, A., Kothari, M. K., Shah, K., \& Nene, A. (2017). Current Concepts - Congenital Scoliosis. Open Orthop $J ., 28(11), 337-345$. https://doi.org/10.2174/1874325001711010337

Tylman, D., \& Fiałkowski, S. (1983). Transthoracic epiphysiodesis and correction with the Harrington distractor as a method of treatment of idiopathic scoliosis in young children (preliminary report). Chir Narzadow Ruchu Ortop Pol, 48(4), 369-72.

van Loon, P. J. (2008). Clinical detectable tension in the growing body: new and revisited signs in clinical examination in children with postural problems and spinal deformities. Restoration of lordosis on the thoracolumbar junction can correct sagittal and coronal plane deformity. A new (revisited) linked approach on the treatment and etiology of adolescent spinal deformities. Stud Health Technol Inform, 140, 52-8.

Weiss, H. (2012). Inclusion criteria for physical therapy intervention studies on scoliosis - a review of the literature. Stud Health Technol Inform, 176, 350-353.

Wilczyński, J. (2012). Analysis of physiological spinal curvatures in girls with scoliosis. Medical Studies, 28(4), 27-36.

Yaszay, B., Bastrom, T. P., \& Bartley, C. E., et al. (2017). The effects of the three-dimensional deformity of adolescent idiopathic scoliosis on pulmonary function. Eur Spine J., 26(6), 1658-1664. https://doi.org/10.1007/s00586-016-4694-y

\section{Copyrights}

Copyright for this article is retained by the author(s), with first publication rights granted to the journal.

This is an open-access article distributed under the terms and conditions of the Creative Commons Attribution license (http://creativecommons.org/licenses/by/4.0/). 